\title{
The dream of staying clean: Lotus and biomimetic surfaces
}

\author{
Andreas Solga, Zdenek Cerman, Boris F Striffler, Manuel Spaeth and \\ Wilhelm Barthlott \\ Nees Institute for Biodiversity of Plants, University of Bonn, Meckenheimer Allee 170, D-53115 Bonn, \\ Germany \\ E-mail:spaeth@uni-bonn.de
}

Received 2 May 2007

Accepted for publication 14 August 2007

Published 16 October 2007

Online at stacks.iop.org/BB/2/S126

\begin{abstract}
The Lotus has been the symbol of purity for thousands of years; contaminations and pathogens are washed off the surfaces of Lotus and some other plants with rain or even dew. After the introduction of scanning electron microscopy, we were able to resolve the mechanism behind this phenomenon. It took some further decades before in-depth studies on self-cleaning with plants were conducted and the effect could be understood in detail. We identified extreme water-repellency ('superhydrophobicity'), characterized by very high contact angles and low sliding angles, as the prerequisite for self-cleaning properties. We could show that the combination of two factors is necessary for obtaining a high degree of water-repellency: (1) low energy surfaces being hydrophobic and (2) surface structures that significantly increase hydrophobicity. It is suggested that this mechanism plays an important role in the protection of plants against pathogens. Our technological application of this effect has resulted in the development of successful, eco-friendly and sustainable industrial products. Another interesting property was found with superhydrophobic surfaces of certain aquatic and semi-aquatic plants and animals: here a layer of air under water is retained. We present a new approach of using this feature for creating structured, air-retaining surfaces for technical underwater applications. It is proposed that such surfaces can reduce significantly the drag of large ships. We conclude that basic biological research is of particular importance for true innovation. Our research on superhydrophobic self-cleaning biological surfaces and the development of similar engineered materials suggests that biomimicry is a matter of multi-stage processes rather than a simple copying of biological developments.
\end{abstract}

(Some figures in this article are in colour only in the electronic version)

\section{Introduction}

In many fields of technology, limits have been reached and therefore alternative approaches to traditional engineering must be found to arrive at innovative solutions. One of the most promising of those approaches is biomimicry, the taking of ideas and concepts from nature and implementing them in a field of technology (Ayre 2003). Even though this concept is not really new, it recently has become very much en vogue (Forbes 2005, Vincent et al 2006).

Considering that nature provides a pool of several million species (Hassan et al 2005) from which any number of models can be selected for closer examination, the popularity of biomimicry seems indeed justified. Moreover, the majority of organisms evolved over millions of years under high evolutionary pressure. This evolution produced sophisticated properties and structures which rarely overlap with methods and products made by man.

When trying to include biology in engineering, two fundamentally different approaches are possible: (1) you look for a specific biological system that serves as a model for an already existing technical problem; (2) you scan the flora and fauna for interesting biological phenomena, and subsequently you study these phenomena and try to transfer them into technology. When choosing the second mode you may find solutions to problems which have not yet been identified as 
such. The action of cleaning is an example of this: everybody is (or rather was) aware of the fact that things do not clean themselves and that resources and power are necessary to remove dirt. The assumption about the inevitability of cleaning had to be reassessed when it became clear that certain surfaces provide a mechanism to minimize the accumulation of dirt passively.

What we present here is an example of the second approach, derived from basic research. The starting point was classic work in plant systematics that aimed at assessing the value of certain surface structures for taxonomic differentiation (cf Barthlott and Ehler (1977), Barthlott and Wollenweber (1981), Barthlott (1989), Barthlott et al (1998)). Most surprisingly, the investigation of potential taxonomic characters led to the discovery and interpretation of principles that have set off an avalanche in material sciences and that can be regarded as a 'by-product' of basic research in botany.

\section{Self-cleaning plants: discovery and exploration}

More than two thousand years ago it was observed that some plants have almost always clean leaves despite their 'dirty' habitats. However, this phenomenon could not be explained with scientific accuracy until the second half of the 20th century. The Lotus Flower (Nelumbo nucifera Gaertn.) for instance is a species that typically grows in swamps and shallow waters in eastern Asia and eastern North America (Borsch and Barthlott 1994). The fact that Lotus emerges totally clean from muddy water prompted Buddhists to declare it a symbol of purity (Ward 1952). A phenomenon that is closely connected with the dirt-free leaves was described by the German all-round genius Johann Wolfgang von Goethe: 'On some sorts of leaves, raindrops take a clear, spherical shape without spreading, which probably has to be ascribed to some kind of evaporated essence' (Goethe 1817-1822: Verstäubung, Verdunstung, Vertropfung). A relationship between low wettability and purity of plant leaves was suspected in later studies (e.g. Engel (1939)); however, the mechanism remained a secret until the development of the high-resolution scanning electron microscope (SEM), introduced in the mid-1960s (Goldstein et al 1981). Now it was possible to explore the micro- and upper nanometre scale and to visualize the ultrastructure of plant surfaces. SEM images provided the key for the correct interpretation of the relationship between surface structure on one hand and the susceptibility of plants to get contaminated on the other (Barthlott and Ehler 1977, Barthlott and Wollenweber 1981). At the end of the 1980s the technological relevance of the self-cleaning phenomenon came into focus (Barthlott 1990). The first comprehensive experimental study on selfcleaning which included a large number of plant species and various contaminants was conducted by Barthlott and Neinhuis (1997) at the University of Bonn, Germany. A second survey (Neinhuis and Barthlott 1997) investigated the micromorphological characteristics of numerous anti-adhesive plant surfaces. Their results pointed to a structural basis of effective self-cleaning. Subsequently, erosion of the surface microstructure and the resulting loss of susceptibility to contamination during the growing season were examined (Neinhuis and Barthlott 1998). Some recent studies (e.g. Cheng et al (2006), Guo and Liu (2007)) focus rather on wettability than on the assessment of self-cleaning efficiency, even though their titles imply something different. It should be noted that self-cleaning properties are not restricted to plants and that they can also be found in certain groups of animals (e.g. Wagner et al (1996), see below).

\section{Self-cleaning properties of superhydrophobic surfaces}

Recently, several reviews on superhydrophobic self-cleaning plant surfaces have been published (e.g. Blossey (2003), Bargel et al $(2004,2006))$. The main points are as follows. The basic requirement for self-cleaning properties is extreme water-repellency, usually referred to as 'superhydrophobicity'. The term superhydrophobicity is neither clearly defined nor consistently used in the literature. It generally means that surfaces exhibit static contact angles $\geqslant 140^{\circ}$. Extreme waterrepellency implies further characteristics such as very low contact angle hysteresis, low water roll-off angles and low water-holding capacity (Haines et al 1985, Öner and McCarthy 2000, Patankar 2004b, Marmur 2006a). It is not possible to produce contact angles that exceed $120^{\circ}$ (Nishino et al 1999) on smooth surfaces without any texture or only by way of hydrophobic surface chemistry. A second ingredient, surface roughness, is required to achieve superhydrophobicity (Cassie and Baxter 1944, Adam 1963, Dettre and Johnson 1964). If a surface is structured in the micro- or nanometre range, the water-air interface of a droplet lying on it is enlarged and the capillary forces between droplet and surface are significantly reduced (Herminghaus 2000). As a consequence, the droplet takes an almost spherical shape and usually rolls off easily. Such surfaces have been termed 'low energy surfaces' (De Gennes et al 2004, Patankar 2004a).

The behavior of droplets on low energy surfaces prompted Quéré (2002) to talk about 'fakir droplets'. A particle on a superhydrophobic self-cleaning surface is like a fakir on his bed of nails: the contact area between the particle and the underlying solid is considerably reduced, resulting in very low adhesion forces (Hansen and Autumn 2005). When a droplet appears, the particle, yielding to the prevalent capillary forces, adheres to the droplet instead of the surface. In consequence the particle will be carried away (figure 1). Even strongly hydrophobic substances like soot (Barthlott and Neinhuis 1997) or the powdery dye Sudan Red G (unpublished data) are easily washed off with water only.

Technical surfaces with contact angles distinctly exceeding $170^{\circ}$ (close to the theoretical maximum of $180^{\circ}$ ) have been created by combining hydrophobicity and surface roughness (Onda et al 1996, Hosono et al 2005). Chen et al (1999) were the first who reported that very high contact angles are not inevitably linked with an easy movement of a droplet over a surface. They presented a surface exhibiting a contact angle of $169^{\circ}$ on which droplets stuck even when the surface was held upside down. Since this observation many authors 


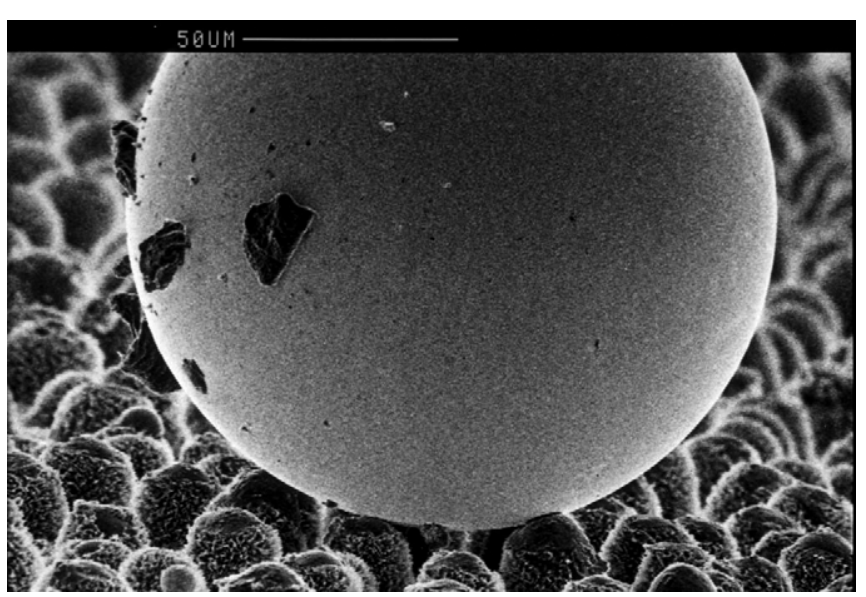

Figure 1. Droplet on a Lotus leaf. Particles adhere not to the leaf surface but to the droplet (Source: Barthlott and Neinhuis 1997).

have investigated the impact of wetting regimes on the dynamic behavior of droplets on rough surfaces (Lafuma and Quéré 2003). In sum, the dynamics of water depend on whether a homogenous or a composite wetting is present. If the droplet wets the grooves between surface structures (homogenous wetting, Wenzel regime) high energy is required to move the liquid on the surface. On the other hand, if the grooves stay dry (composite wetting, Cassie regime) droplets can move across the surface easily. The current regime depends on stable equilibrium states influenced by surface geometry, on how the droplets are formed and on external factors such as e.g. pressure. To obtain desired properties such as self-cleaning or drag-reduction the Cassie regime must be present and also energetically favored (Marmur 2003).

\section{Characteristics of superhydrophobic self-cleaning plant surfaces}

All terrestrial plant species are covered with a waxy layer consisting mainly of the biopolymer Cutin and various lipids. This layer is called the cuticle and is indispensable because it protects the plant from uncontrolled water losses (Martin and Juniper 1970). Plants with superhydrophobic self-cleaning properties almost always possess an additional superimposed covering that consists of a dense layer of three-dimensional epicuticular 'waxes'. These crystals self-assemble and consist mainly of hydrocarbons, primary and secondary alcohols and ketones (Jeffree et al 1975, Cutler et al 1982, Koch et al 2004, 2006a, 2006b). Their chemistry makes the surface hydrophobic. The crystals are $\sim 200 \mathrm{~nm}$ to $5 \mu \mathrm{m}$ in size and occur in a remarkable variety (e.g. Jeffree 1986, Barthlott et al 1998). However, it turned out that the shape of the crystals is of minor importance for the degree of water-repellency and the efficiency of the self-cleaning mechanism (Barthlott and Neinhuis 1997).

The most common (though not the most effective) combination found in plants for achieving self-cleaning properties is convex epidermal cells and 'platelet'-shaped crystals (Barthlott et al 1998). In contrast to plants with limited anti-adhesive properties, those with highly and enduringly efficient self-cleaning surfaces feature a clear hierarchical composition with a rough structure in the region of $\sim 10$ $50 \mu \mathrm{m}$ and a fine structure in the region of $\sim 0.5-2 \mu \mathrm{m}$ (Barthlott 1981, Otten and Herminghaus 2004). Two examples for such a hierarchical composition are given in figure 2 . Although the self-cleaning effect can be achieved with different kinds of structures, experiments have shown that extreme water-repellency and very effective self-cleaning properties strongly depend on aspect ratios and structure densities of the micro- and nanostructured surfaces (Fürstner et al 2005).

\section{The advantages of being superhydrophobic and clean}

The evolutionary benefits of sophisticated superhydrophobic surfaces are diverse. With plants, a water film affects the gas exchange which is crucial for many physiological processes (Brewer and Smith 1994, Brewer 1996). This is true particularly for the underside of the leaf where the
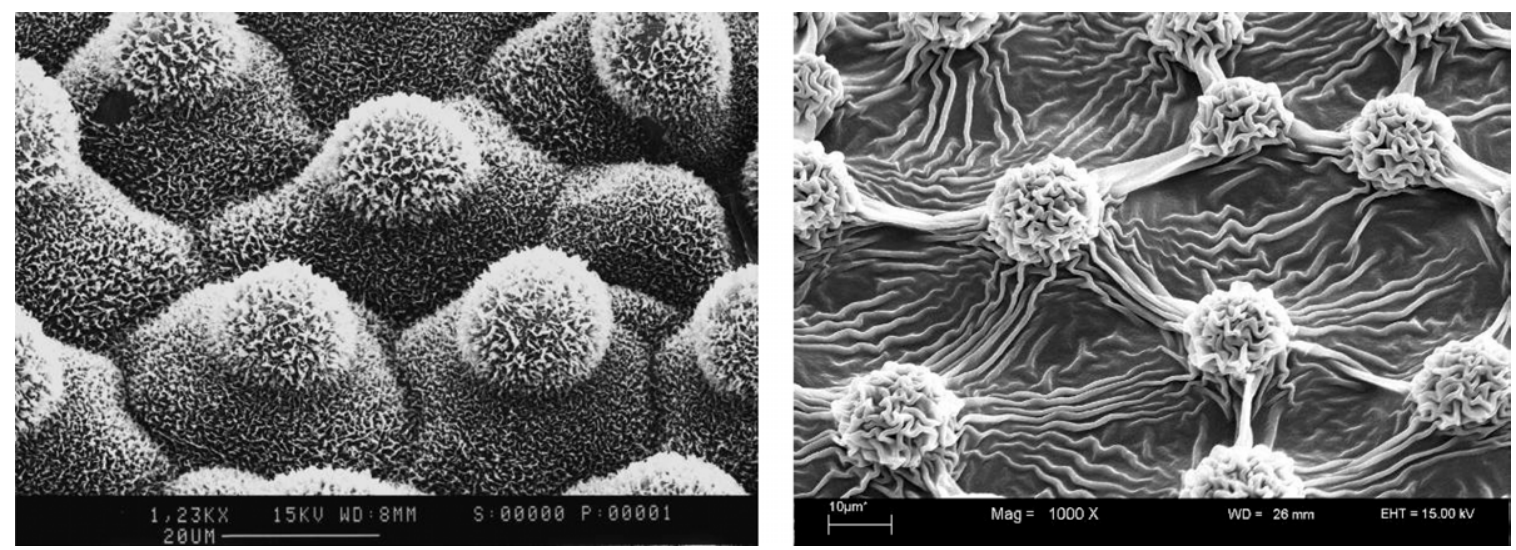

Figure 2. SEM micrographs of the Taro (Colocasia esculenta) and the Elephant Ear (Alocasia macrorrhiza). The upper surface of Colocasia (left) is characterized by convex hexagonal cells with centrally placed papillae and a dense cover of wax platelets. The lower surface of Alocasia (right) shows papillose cells and prominent cuticular folds. 
stomata are usually located. Consequences of a disturbed gas exchange are inhibition of photosynthesis and suppression of plant growth; the latter can even become chronic (Ishibashi and Terashima 1995). This might explain why in numerous plant species the underside of the leaf is less wettable than the upper surface (Smith and McClean 1989). Moreover, a water film significantly increases leaching of nutrients (Tukey 1970). The prevention of a water film has an important side effect: the period during which dissolved air pollutants can damage the plant is distinctly shortened (Haines et al 1985).

Clearly, the ability of a plant to clean itself is an additional benefit. Naturally and artificially emitted dust that is deposited on photosynthetic plant organs causes shading, enhanced reflection, increased leaf temperature, decreased gaseous diffusion and increased transpiration through stomata and cuticle (Thompson et al 1984, Eveling 1986, Hirano et al 1995, Sharifi et al 1997). As a result, the photosynthetic rate is reduced and the plant gets under stress sometimes to the point of damage to its surface (Eveling 1986).

Another important function of the self-cleaning mechanism is its role in the protection against pathogen attacks. Spores of pathogenic fungi are completely washed off surfaces of certain crops with well-developed epicuticular waxes, provided that the surface microstructure is intact (Neinhuis et al 1992). Moreover, a dense layer of wax crystals makes it more difficult for fungi to penetrate a plant surface (Schwab et al 1995). The almost permanent dryness of superhydrophobic self-cleaning surfaces is an obstacle particularly to pathogens producing spores which require free water for germination (Juniper 1991).

In the animal kingdom, it is flying insects that profit most from water-repellent and self-cleaning surfaces. Flight capabilities do not suffer by additional weight when contaminants are constantly removed by dew (Wagner et al 1996, Cong et al 2004).

\section{From plant leaves to technical surfaces}

Self-cleaning is based on a hydrophobic chemistry and a microscopic to nanoscopic surface geometry: a purely physico-chemical effect. When this became evident we started thinking about the potential of this discovery in practice and in everyday life. As described in the introduction, nobody ever considered that things might clean themselves when their surface is modified. In order to prove the transfer of the effect to be technically feasible, we developed technical prototypes: ordinary Formica plates were coated with polytetrafluoroethylene powder with a mean particle size of several micrometres. The hydrophobic particles and their conglomerates, fixed on the plates with glue, substituted both the microstructure of the natural surface and the hydrophobic chemistry of its waxes. Soot scattered on these plates could get completely removed by a short sprinkling (figure 3 ). Despite the excellent performance of the prototypes, industry representatives did not show any interest until a patent on technical micro- and nanostructured self-cleaning surfaces was assigned (Barthlott 1998). This patent and the introduction of the trademark Lotus-Effect ${ }^{\circledR}$ were the go-ahead

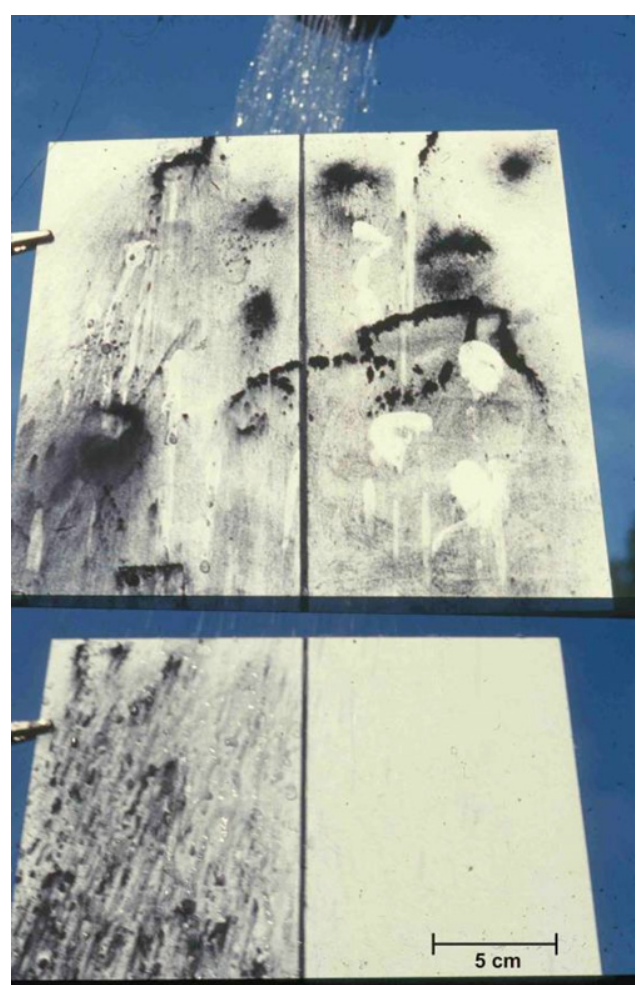

Figure 3. Formica plates with micro- and nanostructured superhydrophobic surfaces.

for the creation of a large cooperation project comprising manufacturers of facade paints and roof tiles, producers of lacquer additives, plastics and textiles and a leading company in specialty chemistry (see www.lotus-effect.com). The cooperation partners carried out extensive research on optimal particle sizes and size distributions as well as on the most stable binding agents and substances for hydrophobization. In the meantime, a second patent for non-permanent applications has been assigned (Barthlott and Neinhuis 2000) and firms have applied for more than 200 depending patents.

The currently most successful product with superhydrophobic self-cleaning properties is a facade paint launched in 1999 (figure 4). In the meantime, the manufacturer of the paint has also marketed a rendering with self-cleaning properties.

In a recent project called 'Building protection by lotuseffect' we investigated whether micro- and nanostructured self-cleaning surfaces reduce biodeterioration. Numerous studies have shown that certain bacteria, fungi and algae are able to colonize facades, roof tiles, building stone, concrete and even glass (Bock and Sand 1993, Warscheid and Braams 2000). These organisms not only produce optical disturbances; due to the release of organic and inorganic acids, they also cause serious damage (Warscheid and Krumbein 1994). The latter has been estimated at 24 billion $€$ per year in Germany alone (Flemming 1995). The common way to prevent biodeterioration so far has been to add biocides to building materials, particularly to facade paints. Since these biocides are gradually leached and, due to their toxicity, give cause for environmental concern, an ecofriendly alternative has been overdue. The project comprised 


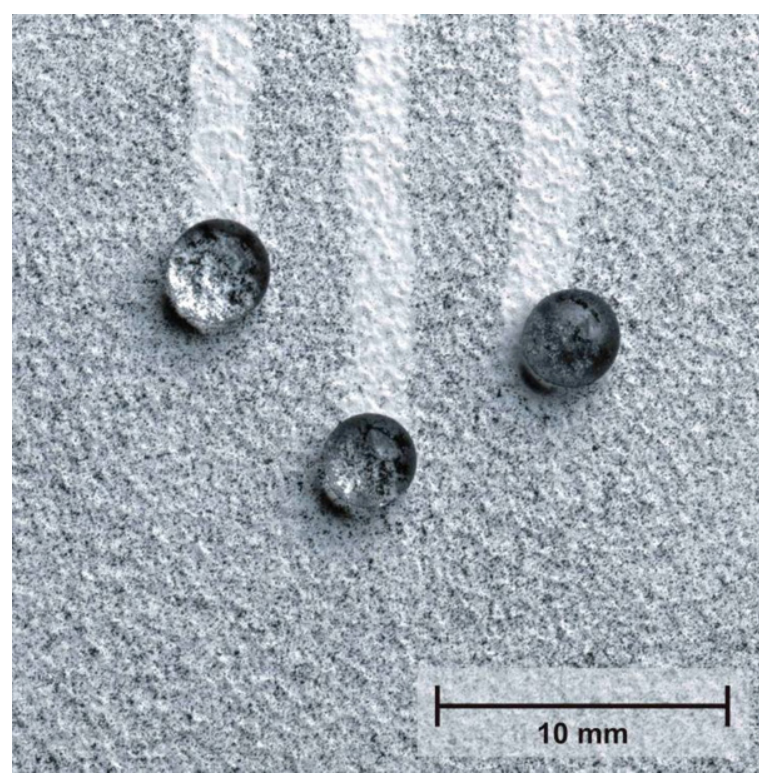

Figure 4. Dust is eliminated from the Lotus-Effect ${ }^{\mathbb{R}}$ facade paint by droplets rolling off (@ Sto AG).

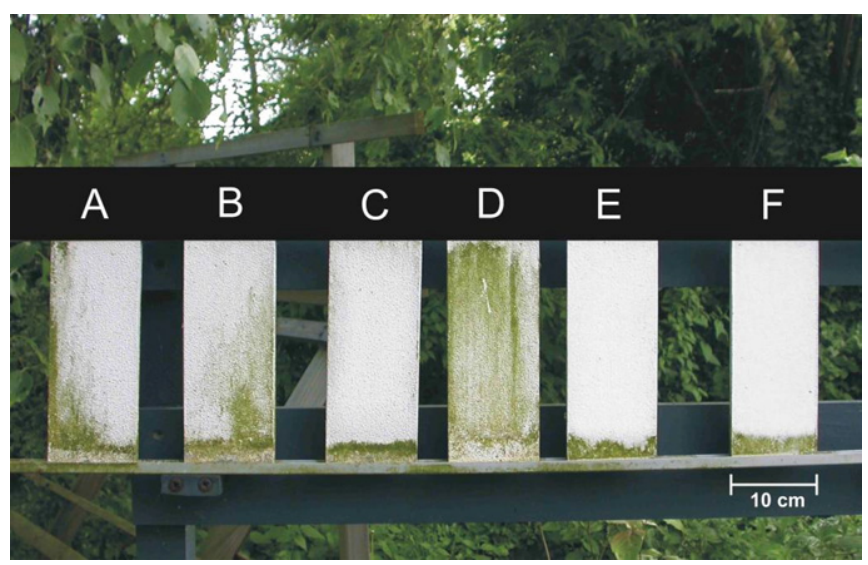

Figure 5. Conventional (A-D) and Lotus-Effect ${ }^{\circledR}(E-F)$ facade paint specimens after six years of exposure under deciduous trees.

both the exposure of test specimens in the field and the development of a laboratory standard method suitable for comparing conventional and biomimetic functional surfaces with regard to their susceptibility to algae and mold infestation (Spaeth et al 2006). A partial result of the studies is given in figure 5. After six years of exposure under deciduous trees, the superhydrophobic self-cleaning test specimens (EF) were distinctly less covered with green algae than samples of conventional paints (A-D). Algae could colonize the biomimetic surfaces only at the bases where the specimens were periodically inundated by rainwater. The findings of the project allowed us to conclude that functional self-cleaning paints in fact provide an efficient alternative to conventional paints furnished with biocides.

Other self-cleaning products have been marketed apart from the above-mentioned facade paint. A cooperation partner who specializes in performance materials developed a coating for glasses. In the meantime, self-cleaning glasses have been installed in sensors of traffic control units on German
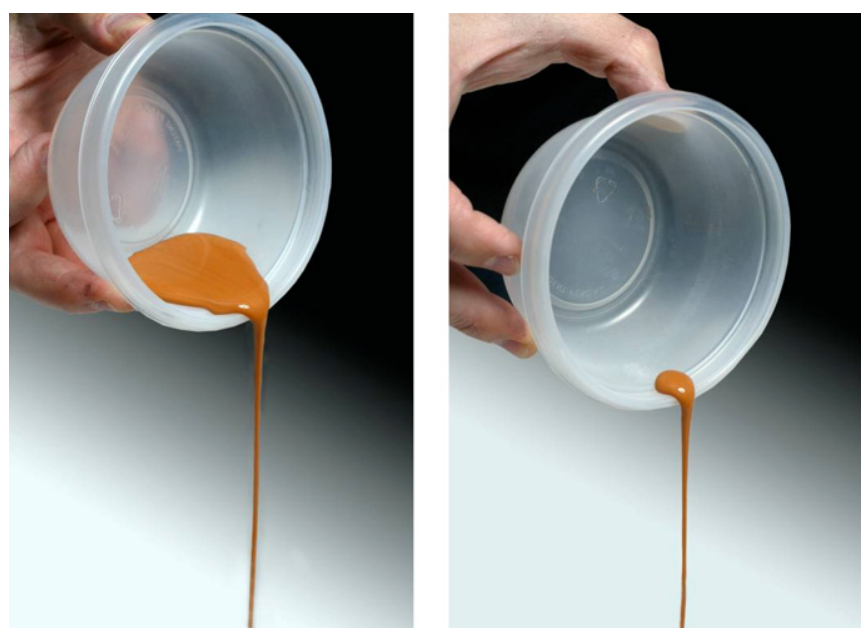

Figure 6. A container furnished with Aeroxide $\mathrm{LE}^{\circledR}$ can be emptied without any residues (@ Degussa AG)

autobahns. Another partner offers a nano-particle powder for multipurpose applications (Nun et al 2002). Containers or cannulas furnished with this powder can be emptied without any residues (figure 6). This property makes them attractive particularly for the medical sector and utilization in laboratories. The manufacturer of this powder has also developed a spray for generating self-cleaning films on various substrata. These films are non-permanent and can, if no longer required, simply be removed by wiping. Possible applications for the spray are different kinds of impregnation, e.g. of garden furniture. In the near future, the introduction of building textiles including awnings, tents and flags is to be expected.

\section{Advantages and limitations}

The benefit derived from the application of superhydrophobic self-cleaning surfaces is evident: large quantities of energy, water and cleaning agents can be saved if active cleaning becomes unnecessary. Therefore, superhydrophobic self-cleaning surfaces make a major contribution towards sustainability and environmental protection. As running water is required for carrying away contaminants, the employment of such surfaces is practical particularly in places which are exposed to rain. Correspondingly, many indoor applications such as wallpapers, net curtains and furniture are not to be considered. Surfactants in soaps and cleaning agents used in the household reduce water surface tension; as a result, also superhydrophobic surfaces, e.g. of sanitary ceramics, can get wet. Another desirable field of applications would be optical lenses, for instance self-cleaning and always-dry eyeglasses. Unfortunately, surface microstructures affect diffraction and thus change the optical properties of lenses.

Although the creation of durable superhydrophobic surfaces has been successful in individual cases (e.g. Nakajima et al 2000), long-term stability is still the most critical challenge (Wulf et al 2002). It is evident that surfaces structured on the micro- or nanometre scale are more sensitive to mechanical stress than common surfaces. Abrasion by 


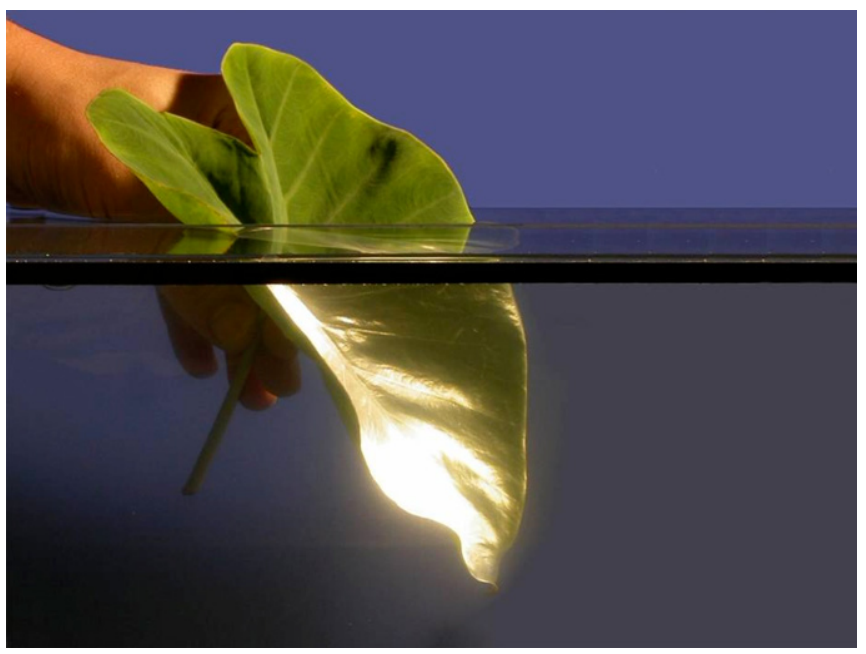

Figure 7. Partially submerged leaf of the Taro (Colocasia esculenta). The silvery shine results from air being trapped between the structures of the leaf surface.

rain, hail and dust as well as aging and decay due to UV radiation causes damage. For the recovery of affected surfaces, two different approaches should be taken into account: (1) a passive regeneration of the micro- or nanostructure by selfassembly and (2) an active repair process. The first approach again is inspired by nature: it has been observed in many different plant species that wax crystals of the original shape reappear some days after their disturbance (Wolter et al 1988, Neinhuis et al 2001, Koch et al 2004, 2006b). Recent work suggests that regeneration of technical superhydrophobic surfaces by self-assembly also may be possible (e.g. Schondelmaier et al 2002, Han et al 2005). Taking the second approach, we are currently examining repair suspensions with nanoparticles. The intention is that particles are deposited at surface defects and that their conglomerates replace the original structure. As a result, functionality is being recovered.

\section{Further properties of rough surfaces}

It has been known for a long time that superhydrophobic plant leaves, if put under water, display a silvery shine (Ziegenspeck 1942, figure 7). This shine is due to air trapped between the surface structures. Recently, this phenomenon has gained significant interest with regard to drag reduction and the prevention of biofouling (Kim and Kim 2002, Marmur 2006a). Most major studies on air-retaining surfaces for underwater applications have investigated airtrapping properties of existing technical surfaces. Even though effectiveness in drag reduction of 20-50\% was achieved (Balasubramanian et al 2004, Fukagata et al 2006, Henoch et al 2006), this approach is limited by the short time the air film persisted. For instance, Balasubramanian et al reported an air retention period of only $18 \mathrm{~min}$. In other studies the characteristics of surfaces capable of keeping an air film under water have been examined only theoretically. The performance of the models has not been tested in experiments (e.g. Marmur 2006b).

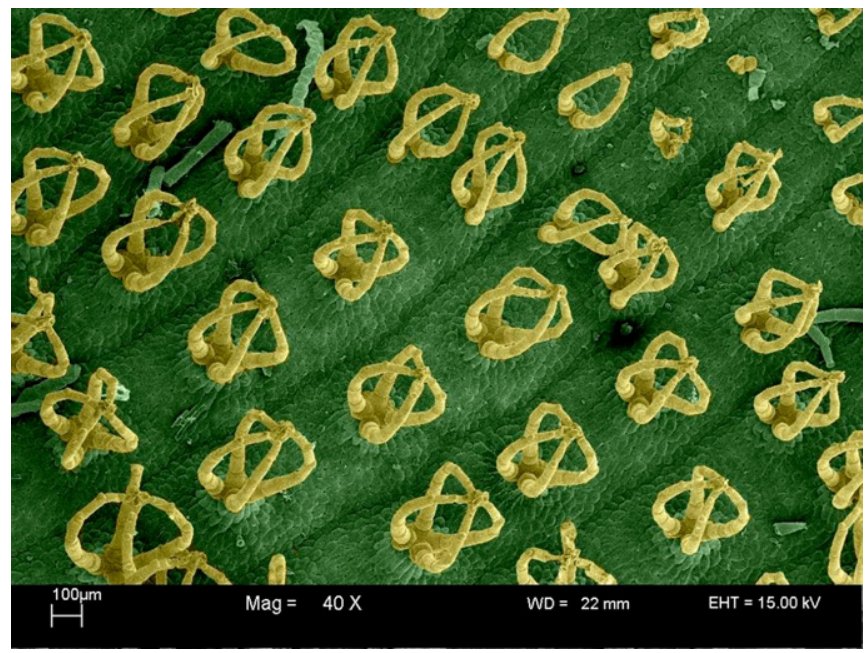

Figure 8. Colored SEM micrograph of the leaf surface of the water fern Salvinia molesta (magnification $\times 40$ ). The hairs are multicellular and have the shape of tiny crowns.

It is plausible that organisms with specific adaptations to floating or diving are more suitable as models for underwater applications than, for example, Lotus which grows above the water surface. Among floating plants, the Water Lettuce Pistia and the Floating Fern Salvinia seem to be the ideal choice for studying underwater air-retaining surfaces. The secret of their effective air retention property is their hairiness: Pistia is covered with large filiform multicellular trichomes; in Salvinia various types of multicellular trichomes have been found (figure 8). Among animals water-repellent hairy structures have evolved several times and with many different purposes. The latter range from respiration as in water bugs, water beetles and the water spider, over insulation as in diving mammals (e.g. Water Shrews) to buoyancy control in most surface-living arthropods (Water Striders or Fishing Spiders (Hu et al 2003)).

We recently have investigated the potential for surfaces of a number of floating plants and semi-aquatic animals to provide technical solutions for the design of air-trapping surfaces that reduce drag. The results suggested that five components should be taken into consideration when a stable long-lasting underwater air film is to be attained: (1) hydrophobicity, (2) hairs with lengths of a few micrometres to several millimeters, (3) additional fine structures such as ridges, hairs or waxes, (4) micro- and nanocavities, (5) elasticity of the structures. We developed a textile prototype in which those components, with the exception of the additional fine structures, are realized. This prototype stays dry for about four days when submerged (figure 9). A patent protecting the technical conversion has been applied for. Soon it will be feasible to make swimwear that does not get wet and thus protects against catching a cold. However, the main goal of the project is to develop surfaces for large-scale applications like ship hulls.

Decreases in drag and the ability of organisms to adhere to these surfaces can be expected by combining such surfaces with already existing technologies used to press air under hulls (e.g. Kodama et al 2002), and it may lead to significant savings in fuel and cleaning costs. 


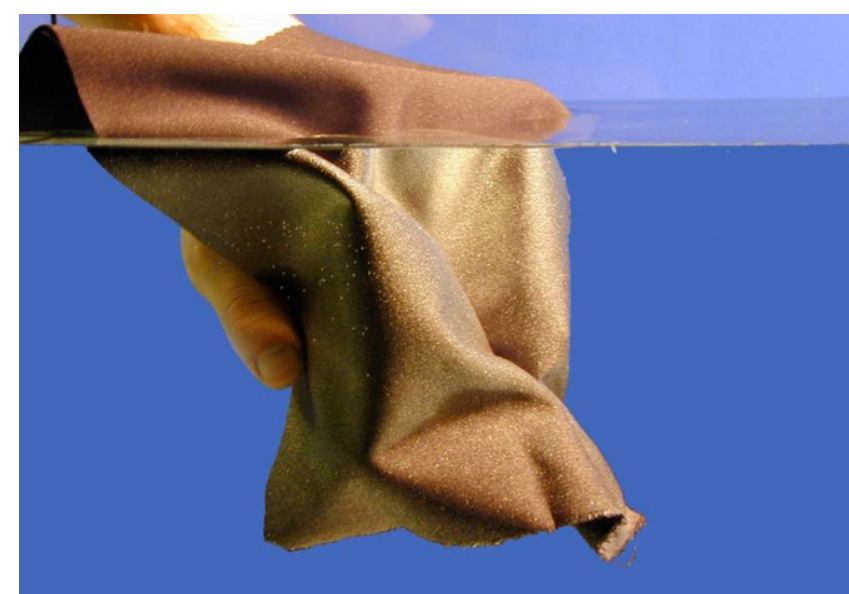

Figure 9. Prototype of a superhydrophobic textile holding an air film under water over several days.

\section{Conclusions}

The example of the Lotus-Effect ${ }^{\circledR}$ clearly shows that biomimicry is dissimilar to a simple copying or duplicating of biological structures. It is rather a multi-stage process that comprises several different steps (cf Cerman et al 2005): (1) discovery of a biological phenomenon, (2) its accurate interpretation, (3) recognizing that the phenomenon can be transferred into technique and construction of a technical prototype, (4) application to products for the market. The example also demonstrates that basic biological research may be of significant importance when aiming to get innovative ideas for technical solutions. From the subsequent development of superhydrophobic air-retaining textiles we conclude that a phenomenon which has been interpreted accurately may give inspiration in completely different subject areas.

\section{Acknowledgments}

We acknowledge gratefully the funding of the Bundesministerium für Bildung und Forschung (BMBF) and of the Deutsche Bundesstiftung Umwelt (DBU). Our industrial partners Degussa, Sto, Erlus, Ferro and ITV Denkendorf kindly supported our work. Gerold Kier, Günter Rebing and our three reviewers suggested valuable improvements on the manuscript. The conference at which the above-described results were presented ('The 2006 International Symposium on Biologically-Inspired Design in Science and Engineering') was supported by Ga Tech's Center for Biologically-Inspired Design and a grant from the Division of Manufacturing Innovation (NSF-DMI \#0614905).

\section{References}

Adam N K 1963 Principles of water-repellency Waterproofing and Water-Repellency ed J L Moilliet (Amsterdam: Elsevier) pp 1-23

Ayre M 2003 Biomimicry - A review. Work package report (Noordwijk, The Netherlands: European Space Research \& Technology Centre (ESTEC), European Space Agency (ESA))
Balasubramanian A K, Miller A C and Rediniotis O K 2004 Microstructured hydrophobic skin for hydrodynamic drag reduction AIAA J. 42 411-4

Bargel H, Barthlott W, Koch K, Schreiber L and Neinhuis C 2004 Plant cuticles: multifunctional interfaces between plant and environment The Evolution of Plant Physiology ed A Hemsley and I Poole (Amsterdam: Elsevier) pp 171-94

Bargel H, Koch K, Cerman Z and Neinhuis C 2006 Evans Review No. 3: structure-function relationships of the plant cuticle and cuticular waxes-a smart material Funct. Plant Biol. 33 893-910

Barthlott W 1981 Epidermal and seed surface characters of plants: systematic applicability and some evolutionary aspects Nord. J. Bot. $1345-55$

Barthlott W 1989 Cuticular surfaces in plants Prog. Bot. 51 48-53

Barthlott W 1990 Scanning electron microscopy of the epidermal surface in plants Application of the Scanning EM in Taxonomy and Functional Morphology ed D Claugher (Oxford: Clarendon) pp 69-94

Barthlott W 1998 Self-cleaning surfaces of objects and process for producing same Patent EP 0772514 B1

Barthlott W and Ehler N 1977 Raster-Elektronenmikroskopie der Epidermis-Oberflächen von Spermatophyten Trop. Subtrop. Pflanzenwelt 19 367-467

Barthlott W and Neinhuis C 1997 Purity of the sacred lotus, or escape from contamination in biological surfaces Planta $2021-8$

Barthlott W and Neinhuis C 2000 Method for producing self-cleaning detachable surfaces Patent, WO 00/58410

Barthlott W, Neinhuis C, Cutler D, Ditsch F, Meusel I, Theisen I and Wilhelmi H 1998 Classification and terminology of plant epicuticular waxes Bot. J. Linn. Soc. 126 237-60

Barthlott W and Wollenweber E 1981 Zur Feinstruktur, Chemie und taxonomischen Signifikanz epicuticularer Wachse und ähnlicher Sekrete Trop. Subtrop. Pfl. 32 7-67

Blossey R 2003 Self-cleaning surfaces-virtual realities Nat. Mater. 2 301-6

Bock E and Sand W 1993 The microbiology of masonry biodeterioration J. Appl. Bact. 74 503-14

Borsch T and Barthlott W 1994 Classification and distribution of the genus Nelumbo Adans. (Nelumbonaceae) Beitr. Biol. Pfl. 68 $421-50$

Brewer C A 1996 What's so bad about being wet all over. Investigating leaf surface wetness Am. Biol. Teach. 58 414-7

Brewer C A and Smith W K 1994 Influence of simulated dewfall on photosynthesis and yield in soybean isolines (Glycine max [L.] cv Williams) with different trichome densities Int. J. Plant Sci. 155 460-6

Cassie A B D and Baxter S 1944 Wettability of porous surfaces Trans. Farad. Soc. 40 546-51

Cerman Z, Barthlott W and Nieder J 2005 Erfindungen der Natur. Bionik - Was wir von Pflanzen und Tieren lernen können (Hamburg: Rowohlt Taschenbuch Verlag)

Chen W, Fadeev A Y, Hsieh M C, Öner D, Youngblood J and McCarthy T J 1999 Ultrahydrophobic and ultralyophobic surfaces: some comments and examples Langmuir 15 3395-9

Cheng Y T, Rodak D E, Wong C A and Hayden C A 2006 Effects of micro- and nano-structures on the self-cleaning behaviour of lotus leaves Nanotechnology 17 1359-62

Cong Q, Chen G-H, Fang Y and Ren L-Q 2004 Super-hydrophobic characteristics of butterfly wing surface J. Bionic Eng. $1249-55$

Cutler D F, Alvin K L and Price C E 1982 The Plant Cuticle (London: Academic)

De Gennes P-G, Brochard-Wyart F and Quéré D 2004 Capillarity and Wetting Phenomena. Drops, Bubbles, Pearls, Waves (Berlin: Springer)

Dettre R H and Johnson R E J 1964 Contact angle hysteresis: II. Contact angle measurements on rough surfaces Contact 
Angle, Wettability, and Adhesion ed F M Fowkes (Washington, DC: American Chemical Society) pp 136-44

Engel H 1939 Das Verhalten der Blätter bei Benetzung mit Wasser Jahrb. Wiss. Bot. 48 816-61

Eveling D W 1986 Scanning electron microscopy of damage by dust deposits to leaves and petals Bot. Gaz. 147 159-65

Flemming H-C 1995 Auswirkungen mikrobieller Materialzerstörung Mikrobielle Materialzerstörung ed H Brill (Stuttgart: Georg Fischer Verlag) pp 15-23

Forbes P 2005 The Gecko's Foot (London: Fourth Estate)

Fukagata K, Kasagi N and Koumoutsakos P 2006 A theoretical prediction of friction drag reduction in turbulent flow by superhydrophobic surfaces Phys. Fluids 18 1-8

Fürstner R, Barthlott W, Neinhuis C and Walzel P 2005 Wetting and self-cleaning properties of artificial superhydrophobic surfaces Langmuir 21 956-61

Goldstein J I, Newbury D E, Echlin P, Joy D C, Fiori C and Lifshin E 1981 Scanning Electron Microscopy and X-Ray Microanalysis (New York: Plenum)

Guo Z and Liu W 2007 Biomimic from the superhydrophobic plant leaves in nature: binary structure and unitary structure Plant Sci. 172 1103-12

Haines B L, Jernstedt J A and Neufeld H S 1985 Direct foliar effect of acid rain: II. Leaf surface characteristics New Phytol. 99 407-16

Han J T, Zheng Y, Ho Cho J, Xu X and Cho K 2005 Stable superhydrophobic organic-inorganic hybrid films by electrostatic self-assembly J. Phys. Chem. B 109 20773-8

Hansen W R and Autumn K 2005 Evidence for self-cleaning in gecko setae Proc. Natl Acad. Sci. 102 385-9

Hassan R, Scholes R and Ash N (ed) 2005 Ecosystems and Human Well-Being: Current State and Trends vol 1 (Washington: Island Press)

Henoch C, Krupenkin T N, Kolodner P, Taylor J A, Hodes M S and Lyons A M 2006 Turbulent drag reduction using superhydrophobic surfaces 3 rd AIAA Flow Control Conference (5-8 June 2006, San Francisco, CA) ed K Breuer (Reston, VA: American Institute of Aeronautics and Astronautics) AIAA Paper 2006-3192

Herminghaus S 2000 Roughness-induced non-wetting Europhys. Lett. 52 165-170

Hirano T, Kiyota M and Aiga I 1995 Physical effects of dust on leaf physiology of cucumber and kidney bean plants Env. Poll. $89255-61$

Hosono E, Fujihara S, Honma I and Zhou H 2005 Superhydrophobic perpendicular nanopin film by the bottom-up process J. Am. Chem. Soc. 127 13458-9

Hu D L, Chan B and Bush J W M 2003 The hydrodynamics of water strider locomotion Nature 424 663-6

Ishibashi M and Terashima I 1995 Effects of continuous leaf wetness on photosynthesis: adverse aspects of rainfall Plant Cell Env. 18 431-8

Jeffree C E 1986 The cuticle, epicuticular waxes and trichomes of plants, with reference to their structure, function and evolution Insects and the Plant Surface ed B E Juniper and S R Southwood (London: Edward Arnold) pp 23-63

Jeffree C E, Baker E A and Holloway P J 1975 Ultrastructure and recrystallization of plant epicuticular waxes New Phytol. 75 539-49

Juniper B E 1991 The leaf from the inside and the outside: a microbes perspective Microbial Ecology of Leaves ed J H Andrews and S S Hirano (Berlin: Springer) pp 21-42

Kim J and Kim C-J 2002 Nanostructured surfaces for dramatic reduction of flow resistance in droplet-based microfluidics Proc. 15th IEEE Int. Conf. on Micro Electro Mechanical Systems (20-24 Jan. 2002, Las Vegas) (Washington, DC: Institute of Electrical and Electronics Engineers) pp 479-82
Koch K, Barthlott W, Koch S, Hommes A, Wandelt K, Mamdouh W, De-Feyter S and Broekmann P 2006a Structural analysis of wheat wax (Triticum aestivum, c.v. 'Naturastar' L.): from the molecular level to three dimensional crystals Planta $223258-70$

Koch K, Dommisse A and Barthlott W 2006b Chemistry and crystal growth of plant wax tubules of lotus (Nelumbo nucifera) and nasturtium (Tropaeolum majus) leaves on technical substrates Cryst. Growth Des. 6 2571-8

Koch K, Neinhuis C, Ensikat H-J and Barthlott W 2004 Self assembly of epicuticular waxes on living plant surfaces imaged by atomic force microscopy (AFM) J. Exp. Bot. $55711-8$

Kodama Y, Kakugawa A, Takahashi T, Nagaya S and Sugiyama K 2002 Microbubbles: drag reduction mechanism and applicability to ships 24th Symposium on Naval Hydrodynamics (Fukuoka, Japan) ed Naval Studies Board (Washington: National Academies Press) pp 1-20

Lafuma A and Quéré D 2003 Superhydrophobic states Nat. Mater 2 457-460

Marmur A 2003 Wetting on hydrophobic rough surfaces: to be heterogeneous or not to be? Langmuir 19 8343-8

Marmur A 2006a Super-hydrophobicity fundamentals: implications to biofouling prevention Biofouling 22 107-15

Marmur A 2006b Underwater superhydrophobicity: theoretical feasibility Langmuir 22 1400-2

Martin J T and Juniper B E 1970 The Cuticles of Plants (London: Edward Arnold)

Nakajima A, Hashimoto K, Watanabe T, Takai K, Yamauchi G and Fujishima A 2000 Transparent superhydrophobic thin films with self-cleaning properties Langmuir 16 7044-7

Neinhuis C and Barthlott W 1997 Characterization and distribution of water-repellent, self-cleaning plant surfaces Ann. Bot. $79667-77$

Neinhuis C and Barthlott W 1998 Seasonal changes of leaf surface contamination in beech, oak and ginko in relation to leaf micromorphology and wettability New Phytol. 138 91-8

Neinhuis C, Koch K and Barthlott W 2001 Movement and regeneration of epicuticular waxes through plant cuticles Planta 213 427-34

Neinhuis C, Wolter M and Barthlott W 1992 Epicuticular wax of Brassica oleracea: changes of microstructure and ability to be contaminated of leaf surfaces after application of TRITON X-100 J. Plant Dis. Prot. 99 542-9

Nishino T, Meguro M, Nakamae K, Matsushita M and Ueda Y 1999 The lowest surface free energy based on $-\mathrm{CF}_{3}$ alignment Langmuir 15 4321-3

Nun E, Oles M and Schleich B 2002 Lotus-Effect $^{\mathbb{R}}{ }_{\text {-surfaces }}$ Macromol. Symp. 187 677-82

Onda T, Shibuichi S, Satoh N and Tsujii K 1996 Super-water-repellent fractal surfaces Langmuir 12 2125-7

Öner D and McCarthy T J 2000 Ultrahydrophobic surfaces. Effects of topography length scales on wettability Langmuir $167777-82$

Otten A and Herminghaus S 2004 How plants keep dry: a physicists point of view Langmuir 20 2405-8

Patankar N A 2004a Mimicking the lotus effect: influence of double roughness structures and slender pillars Langmuir 20 8209-13

Patankar N A 2004b Transition between superhydrophobic states on rough surfaces Langmuir 20 7097-102

Quéré D 2002 Fakir droplets Nat. Mater. 1 14-5

Schondelmaier D, Cramm S, Klingeler R, Morenzin J, Zilkens C and Eberhardt W 2002 Orientation and self-assembly of hydrophobic fluoroalkylsilanes Langmuir 18 6242-5

Schwab M, Noga G and Barthlott W 1995 Bedeutung der Epicuticularwachse für die Pathogenabwehr am Beispiel von Botrytis cinerea-Infektionen bei Kohlrabi und Erbse Gartenbauwissenschaft 60 102-9 
Sharifi M R, Gibson A C and Rundel P W 1997 Surface dust impacts on gas exchange in Mojave Desert shrubs J. Appl. Ecol. 34 837-46

Smith W K and McClean T M 1989 Adaptive relationship between leaf water repellency, stomatal distribution, and gas exchange Am. J. Bot. 76 465-9

Spaeth M, Solga A, Barthlott W and Cerman Z 2006 Funktionale Bautenoberflächen: Wie testet man mikrobiellen Bewuchs? Altbauinstandsetzung 11 203-14

Thompson J R, Mueller P W, Flückiger W and Rutter A J 1984 The effect of dust on photosynthesis and its significance for roadside plants Env. Poll. (Ser. A) 34 171-90

Tukey H B J 1970 The leaching of substances from plants Annu. Rev. Plant. Physiol. 21 305-24

Vincent J, Bogatyreva O, Bogatyrev N, Bowyer A and Pahl A 2006 Biomimetics: its practice and theory J. Roy. Soc. Interface 3 471-82
Wagner T, Neinhuis C and Barthlott W 1996 Wettability and contaminability of insect wings as a function of their sculptures Acta Zool. 77 213-25

Ward W E 1952 The lotus symbol: its meaning in Buddhist art and philosophy J. Aes. Art Crit. 11 135-46

Warscheid T and Braams J 2000 Biodeterioration of stone: a review Int. Biodet. Biodeg. 46 343-68

Warscheid T and Krumbein W E 1994 Biodeterioration processes on inorganic materials and means of countermeasures Mater. Corros. 45 105-13

Wolter M, Barthlott W, Knoche M and Noga G 1988 Concentration effects and regeneration of epicuticular waxes after treatment with Triton X-100 surfactant Angew. Bot. 62 53-62

Wulf M, Wehling A and Reis O 2002 Coatings with self-cleaning properties Macromol. Symp. 187 459-67

Ziegenspeck H 1942 Zur physikalischen Chemie unbenetzbarer besonders bewachster Blätter Kolloid-Zeitschrift 100 401-3 